\title{
THE POTENTIAL OF SPODOPTERA PECTINICORNIS IN CONTROLLING WATER LETTUCE (Pistia stratiotes) IN FIELD
}

\author{
Lyswiana Aphrodyanti, Helda Orbani Rosa, Samharinto \\ Plant Protection Department, Agricultural Faculty, Lambung Mangkurat University \\ Banjarbaru, South Kalimantan, Indonesia \\ Email : aphrodyanti13@yahoo.com
}

\begin{abstract}
Spodoptera pectinicornis is a biological control agent that has a great potential to control water lettuce weeds. Its existence in nature however is still limited, so a mass propagation is needed by rearing $S$. pectinicornis imagoes to produce eggs and to hatch them into larvae of 4 days old. The 4year larvae were then released by putting water lettuces that contained active larvae into the target area. Observation results on the percentage of damage in the watershed location for 5 times of observation consecutively was $25 \%, 50 \%, 50 \%, 75 \%$ and $90 \%$. The magnitude of damage showed that S. pectinicornis was able to adapt well, so it could perform eating activities and cause damage to the water lettuces. Meanwhile, at the release site of rice field, the percentage of damage was $0 \%, 25 \%, 35 \%, 25 \%$ and $10 \%$. The downward trend in the level of $S$. pectinicornis attacks was due to its inability to keep pace with the growth and development of water lettuces. High level of rainfall caused the water lettuces to increase its size and the number of its tillers so that they could colonize these waters. The fact that $S$. pectinicornis still has the ability to destroy the water lettuces gives great hope to the control efforts. However, thorough evaluation and assessment are required on all aspects, such as the biological control agents, weed targets, organisms associated with them, and the state of the environment so as to minimize the possibility of failure in the field.
\end{abstract}

Keywords: augmentation, biological agents, Pistia stratiotes, Spodoptera pectinicornis

\section{INTRODUCTION}

Pistia stratiotes, known as water lettuce, is a weed that is found in almost all tropical and subtropical waters. Invasion of water lettuce can cause damage to infrastructure such as blocked drains, reduce the efficiency of irrigation and hydroelectric power plants (Howard and Harley 1998), lead to the miniaturization of the volume of plankton (Cai, 2006), and become a habitat for mosquito malaria vector Anopheles and Mansonia (FL DEP, 2007, Parsons and Cuthbertson, 2001). Water lettuce belongs to harmful weed or invasive aquatic plants in several states of the United States (USDANRCS, 2012), Australia (Queensland Government, 2016), also in Indonesia (EPPO, 2014 and CABI 2015).

South Kalimantan is one of the widespread deployment areas of water lettuce weeds in Indonesia (EPPO 2014 and CABI 2015), and Spodoptera pectinicornis is found as herbivore on the weeds (Mangoendihardjo et al., 1979). The spread of this insect is quite extensive and allegedly it is one of the native insect of Indonesia because Kunta's research results (1977) show that this insect is found in Asian countries like India, Sri Lanka, Singapore and Indonesia. However, the existence of $S$. pectinicornis has not been able to overtake the growth and development rate of water lettuces in the field, so the manipulation effort is conducted through an augmentation technique by doing a mass propagation of biological agents first before released into the field.

The success of other countries, such as India and Thailand, in controlling water lettuce weeds using $S$. pectinicornis gives great hope that it could also happen in our country, Indonesia. A biological method that has been successful would provide a more permanent and wider scale of control and a minimum negative impact on the environment.

\section{MATERIALS AND METHODS}

The rearing and mass propagating were conducted in screen house and the Entomology Laboratory, Plant Pests and Diseases Department, Agriculture Faculty, Lambung Mangkurat University, from May to October 2016, while the release was 
conducted in Banjar Regency at two locations - watershed and rice field, from September to November, 2016.

\section{Rearing of S. pectinicornis agents in the Laboratory}

S. pectinicornis larvae were bred by supplying the feed of fresh water lettuce until they reached pupal stage. The pupae were collected and placed into a plastic jar with a diameter of $14 \mathrm{~cm}$, at the base of which tissue paper and wet cotton were placed to keep it moist. Male and female imagoes that emerged were transferred into an enclosure and given honey of $10 \%$ on the hanged cotton. The imagoes mated and laid eggs on the water lettuce.

\section{Mass Production of $S$. pectinicornis Biological Control Agents}

Mass production was done by setting up nurturing containers with a diameter of 50 $\mathrm{cm}$. The nurturing containers were covered with gauze cover, and the fresh water lettuces taken from the field were put into the containers. Subsequently, the instar III were invested as much as possible and kept alive until they became pupae and imagoes. The imagoes were allowed to mate and lay eggs. The breeding of biological agents in bulk continued until they reached sufficient number with the estimation of 100 larvae per square meter with the release area of about 200 square meters so that about 20,000 larvae were required to be released.
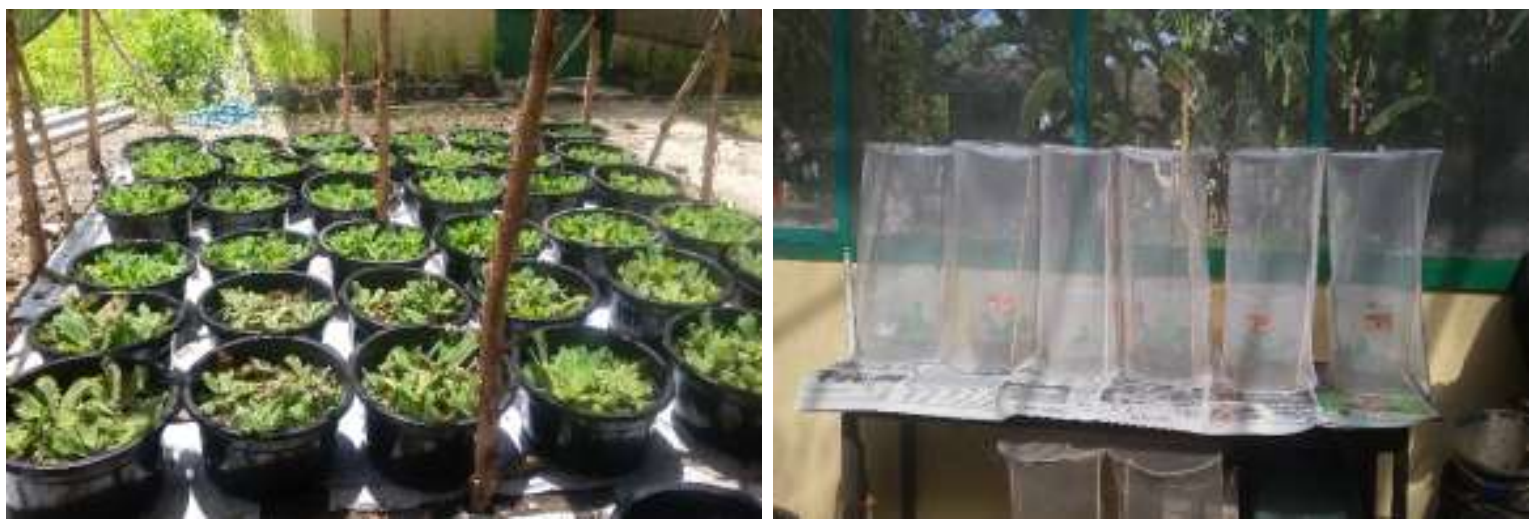

Figure 1 Mass propagation and breeding of S. pectinicornis pupae and imagoe

The rearing of biological agents in bulk was conducted so as to achieve a sufficient number with an estimation of 100 larvae per square meter, with the release area of about 200 square meters, which needed about 20,000 larvae ready to release. According to

\section{The release of S. pectinicornis agents into the field}

The 4-year stadia larvae were invested into waters being invaded by water lettuces the watershed and rice field areas. The release was done 2 times, on the first day and then on the 30th day. The number of larvae to be invested with an estimation of 100 larvae per square meter and the number needed for the release were to be adjusted to the extent of the area to be invested.

\section{Observation}

Observations were made by observing the damage symptoms inflicted and were performed 5 times with an interval of 10 days. As supporting data, observations were carried out on the presence of predators and parasitoids which could represent as one of the limiting factors for the activity of the biological agents.

\section{RESULTS AND DISCUSSION}

\section{Mass propagation and release to the field}

The effort of mass propagation of $S$. pectinicornis showed success as evidenced by the ability of $S$. pectinicornis to complete its life cycle and continue to proliferate normally so as to achieve a sufficient number for the preparation of the release into the field (Figure 1). 
relationship between the number of insects to be released and their establishment in the field.

The release of biological agents in the larval stage was considered very effective because the larvae would attach firmly on the water lettuce leaves, so the possibility of death could be overcome. The release was carried out by spreading the water lettuces containing active larvae evenly in the weed target areas. According to Jolivet (1992), monophagous insects would do the physical, mechanical and chemical selection to select a plant as food, and thus releasing larvae along with the water lettuces originating from mass propagation in the screen house would greatly affect the process of adaptation to the new place.

\section{Damage Percentage}

Observations on the watershed location indicated that the $S$. pectinicornis biological agents clearly showed a very high destructive capability, while at the rice field location it showed a different thing, where the damage tended to decrease (Figure 2).

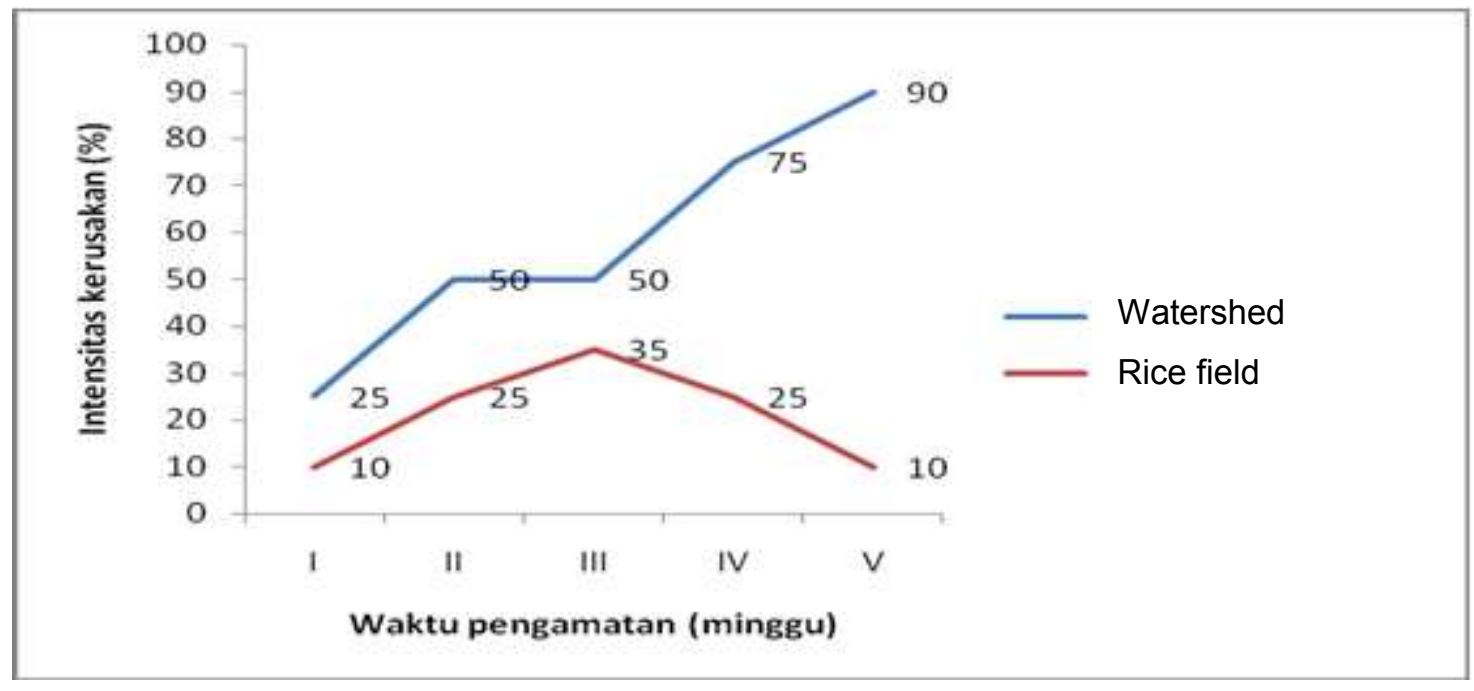

Figure 2. Percentage of damage to water lettuce caused by S. pectinicornis

The percentage of damage in the watershed location for 5 times of observation consecutively was 25\%, 50\%, 50\%, $75 \%$ and $90 \%$. The presence of damage symptom indicated that the biological agents were able to adapt well and conducted eating activity immediately after release. According to Aphrodyanti et al., (2009), S. pectinicornis larvae of instar III and IV had high eating consumption ability so that it could cause severe damage. The success of controlling water lettuce by utilizing S. pectinicornis have been able to replace the use of herbicides in
Thailand (Napompeth, 1990) and a similar statement stated by George in Center et al., (2000) that this control technique has also been able to replace the use of herbicides that is very dangerous because it is used in water areas.

The last observation at this location showed that the $90 \%$ damage reinforced the notion that $S$. pectinicornis biological agent was a potential natural enemy, but it required human intervention to improve its ability to overcome the problem of water lettuce weeds. 

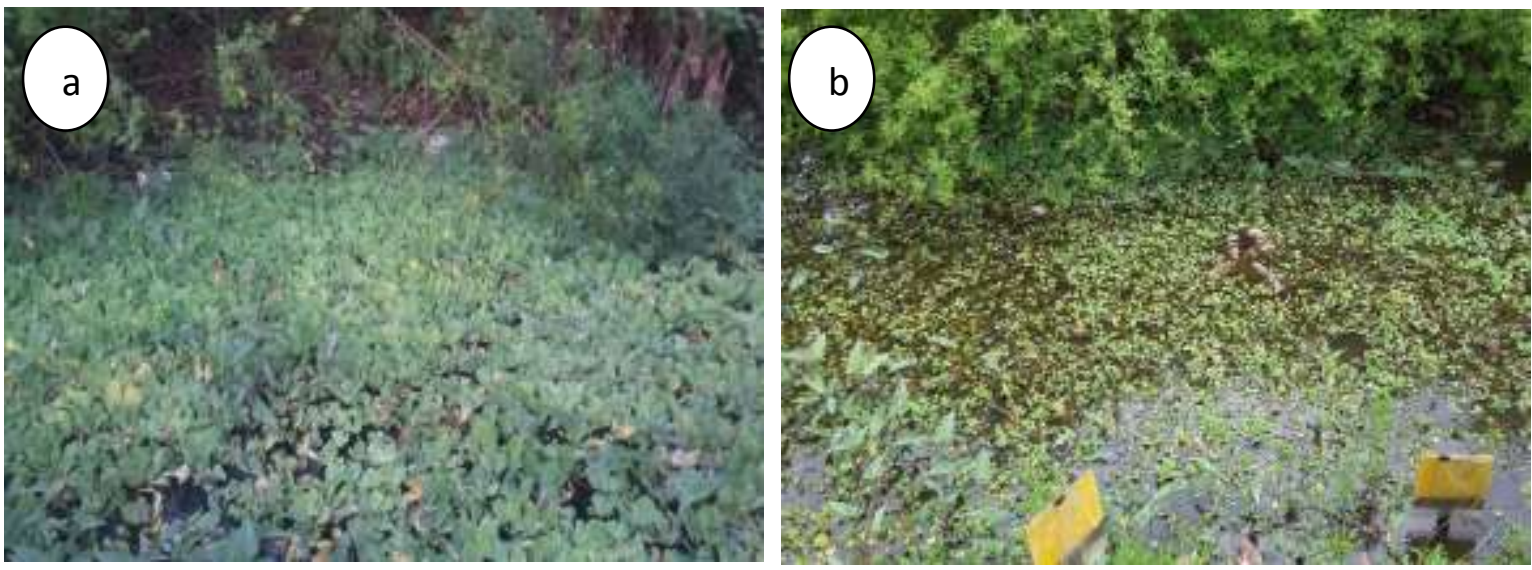

Figure 3. Damage to water lettuce weeds due to S. pectinicornis in watershed location a. Prior to the release and $b$. After the release

Observations in the rice fields showed different results, i.e. the damage percentage of $10 \%, 25 \%, 35 \%, 25 \%$ and $10 \%$. The downward trend in the level of attacks was allegedly due to the inability of $S$. pectinicornis in keeping pace the growth and development of water lettuces that colonized such areas. These weeds multiplied quickly through organ pieces of vegetative stolon and seed production that were instrumental in their reproduction and distribution (Dray \&
Center, 1989). According to Mangoendiharjo (1982) water lettuces would experience optimal growth when the conditions were met, and the improvement of leaves would increase by $10 \%$ and the dry weight would increase by $42 \%$ and the number of individuals would be doubled. The same is stated by Dhahiyat (1989) that water lettuces could double after 10-15 days and required sunlight in sufficient quantity and optimum temperature of $25-30^{\circ} \mathrm{C}$.

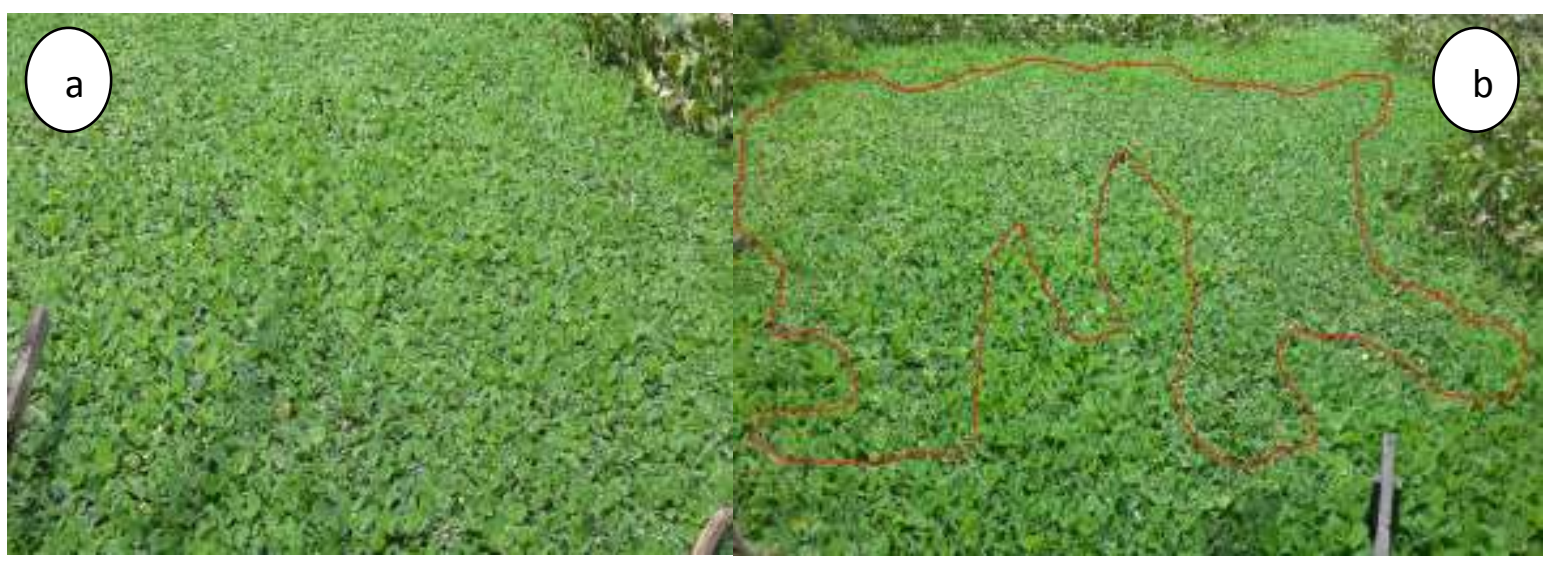

Figure 4. Damage to water lettuce weeds due to $S$. pectinicornis in rice field location a. Prior to the release and $b$. After the release

The release of $S$. pectinicornis in rice fields got impacted by the water condition that was unstable and the swamp overgrown by various types of aquatic weeds caused the development of $S$. pectinicornis to become not so good so the population was also low (Mangoendiharjo, 1982).
The existence of predators and parasitoid associated with $S$. pectinicornis biological agents would affect their activities in the field. As for the predator and parasitoid often encountered were from the class of spiders (Arachnida), insects (Insecta) (Figure $5)$. 

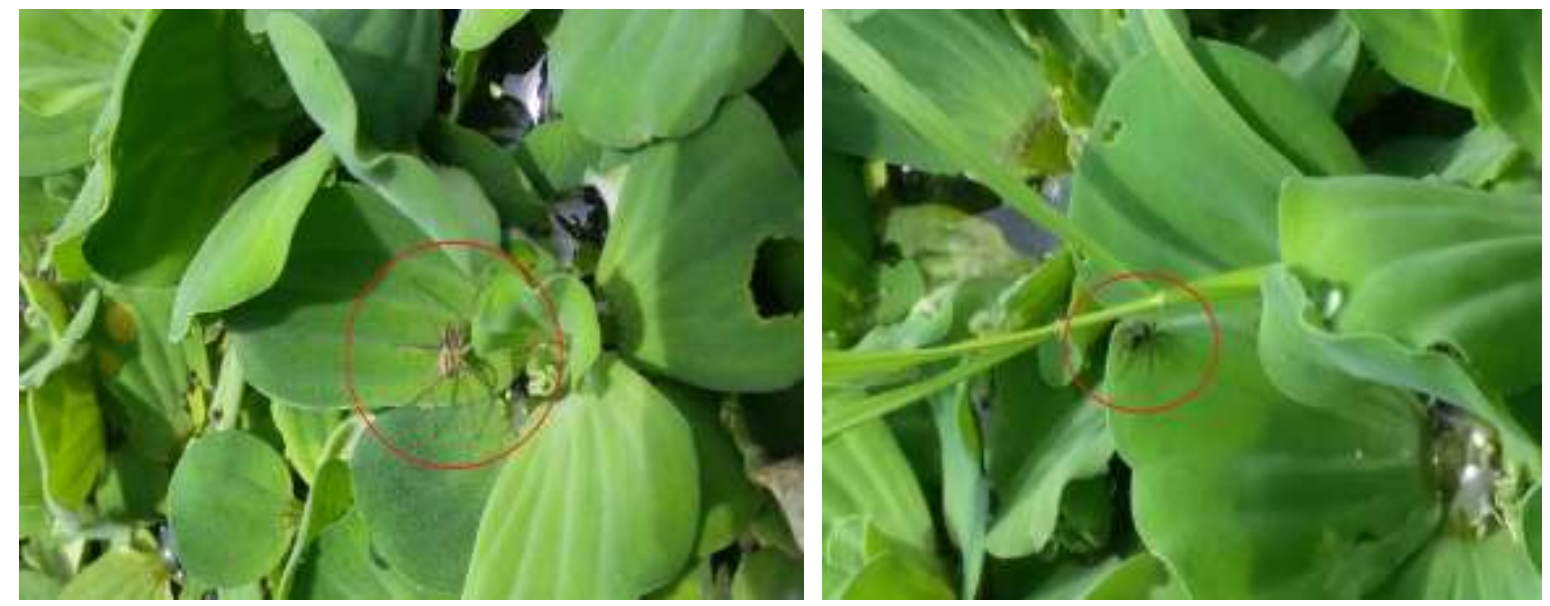

Figure 5. Predators from the class of spiders (arachnids)

Class of insect (Insecta) which acts as a predator obtained from several orders i.e. order of Coleoptera, Hemiptera, Odonata and Hymenoptera while those acting as parasitoid are from the order of Hymenoptera and Diptera. Insects directly caught to attack $S$. pectinicornis were ants (Hymenoptera)

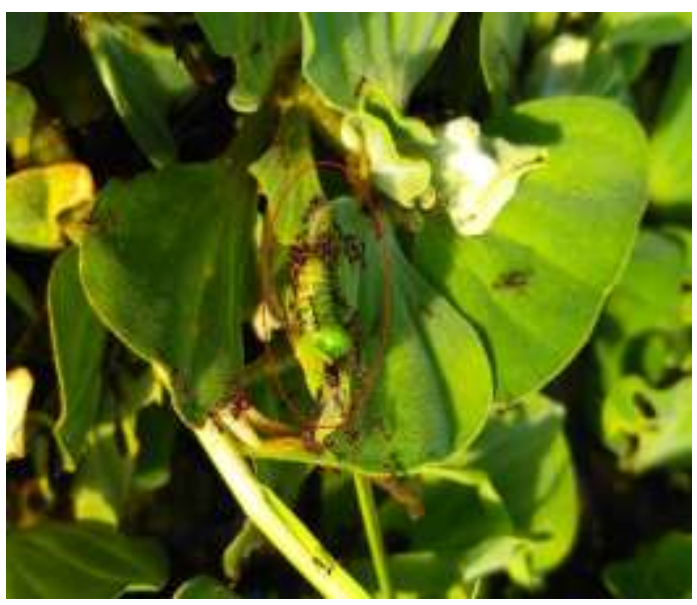

(Figure 6) and according to the observation of Mangoendiharjo (1982) on the water lettuce, Coelosoma sp. (Col: Hydrophilidae) aquatic beetles were often found and there were also many species of ants that became predators against $S$. pectinicornis.

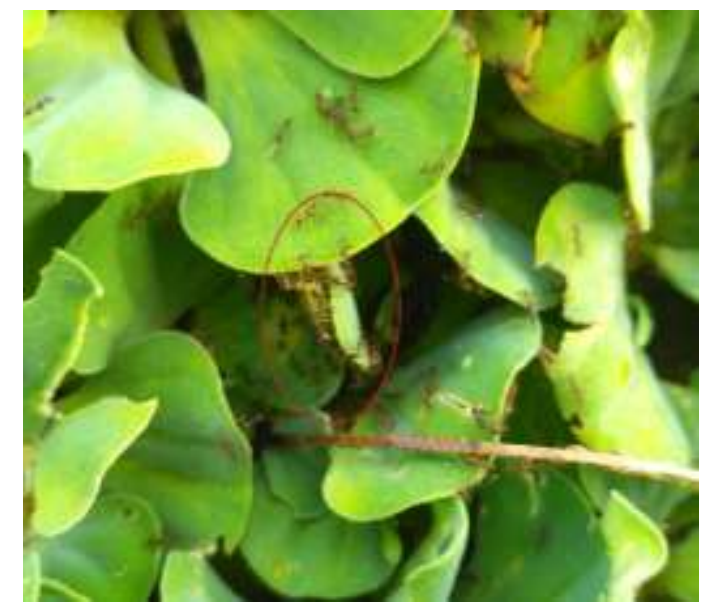

Figure 6 Predator attacks against S. pectinicornis larvae and pupae

The identification result of predator insects was known to be the order of Coleoptera of Carabidae and Coccinellidae families that were predator of eggs or larvae, the order Odonata (dragonflies), the order Hemiptera that was gerridae insect (water straider) of the Gerridae family and ambrysus $s p$ insect of the Naucoridae family.

The types of parasitoids insect were known to be the order of Hymenoptera consisted of the family of Braconidae, Chalcidoidae, and Platygastroidea, whereas from the order of Diptera was from the family of Ephydridae and Anisopodidae.
In some cases, the release of biological agents into the field, there were those that experienced failure as stated by Dray et al., (2001) that S. pectinicornis moth that had been released at 22 places in South Florida from 1990 to 1997 and in some places the population could grow but there were also those that failed to survive. The existence of predators such as fire ants and spiders was one of the causes. A similar thing happened in New Zealand, where 69\% of insects released to control weeds failed to survive in the field. Other things that could cause failure in the release of biological 
agents were things such as the difficulties at the time of collection, maintenance, and the limited number of individuals for release (Memmott et al., 1996). Whereas according to Crawley (1986), bad weather conditions and adaptation to the new climate could cause failure of the release of biological agents.

The final objective of biological control program is to manage the target weeds and reduce their impact, so the implementation phase must consider all aspects of existing resources and the research on the potential of biological control agents would determine the success (Crc Weed Management, 2008).

\section{CONCLUSIONS}

Spodoptera pectinicornis could be reproduced en masse but it is important to consider the availability of feed in a fresh state and to avoid interference from other organisms. The release in the watershed location showed that $S$. pectinicornis was able to adapt well and cause substantial damage to water lettuce weeds. The release in the rice field location showed that $S$. pectinicornis was less able to work optimally, so the damage caused to the water lettuce weeds was low. There were predators and parasitoids associated with $S$. pectinicornis and the water lettuce weeds. It is important to conduct a thorough evaluation and assessment of the S. pectinicornis, the water lettuce weeds, association with other organisms, and the environment condition to minimize the possibility of failure in the field.

\section{REFERENCES}

Aphrodyanti L, Utomo K, Sokisman T. (2009). Biology of Insects Feeding on Weed Spodoptera pectinicornis (Hampson) (Lepidoptera: Noctuidae). Agroscientiae Journal 16: 2 Agustus 2009.

[CABI] Centre for Agriculture and Biosciences International. (2015). Pistia stratiotes (Water lettuce). Invasive species compendium Wallingford. Retrieved on September 29th 2016 from http://www.cabi.org/isc/datasheet/4 $\underline{1496}$

Cai, L. (2006) . Impact of floating vegetation in Shuikou impoundment, Minjiang
River, Fujian Province. Hupo-Kexue 18(3) : 250-254.

Center, T.D., Dray, F.A., \& Vandiver, V.V. Jr. (2000). Biological control with insects: the waterlettuce moth. Retrieved from http://edis.ifas.ufl.edu.

Crawley, M.J. (1986). The population biology of invaders. Philosophical Transaction of the royal Society of London 314: 711-731.

CRC (Cooperative Research Centre) Weed Management. (2008). Best Practice Guide. Release and establishment of weed biological control agents. University of Tasmania.

Dhahiyat Y. (1989). Problems of Aquatic Weeds and the control of their development. In the training of research on natural resources and environment. Bandung, 19 April-5 Mei 1989. pp 1-40. Research Center of Padjajaran University. Bandung.

Dray, Jr., F.A., \& Center, T.D. (1989). Seed production by Pistia stratiotes L. (water lettuce) in the United States. Aquatic Botany 33 (1-2):155-160.

Dray, Jr., F.A., Center, T.D. and Wheeler, G.S.. (2001). Lessons from unsuccessful attempts to establish Spodoptera pectinicornis (Lepidoptera: Noctuidae), a Biological Control Agent of Waterlettuce. Biocontrol Science and Technology, 11: 301-316.

[EPPO] European and Mediterranean Plant Protection Organization (2014). PQR - EPPO Plant Quarantine Retrieval System. Paris. France. Retrieved from http://www.eppo.int/DATABASES/p gr/pqr.htm

[FL DEP] Florida Department of Environmental Protection. (2007). Status of the Aquatic Plant Maintenance Program in Florida Public Waters: Annual Report Fiscal Year 2005-2006. Bureau of Invasive Plant Management. Retrieved from http://www.floridainvasives.org/tool box/reports/aquaticsfy05-06.pdf

Howard, G.W., \& Harley, K.L.S. (1998). How do floating aquatic weeds affect wetland conservation and development. How can these 
Lyswiana Aphrodyanti, Helda Orbani Rosa, Samharinto: The Potential Of Spodoptera

effects be minimized. Wetland Ecology and Management 5: 215225.

Jolivet, P. (1992). Insect and Plant : Paralel Evolution and Adaptations. Second eds. Gainnesville Florida USA: Sanhill Crane Press Inc.

Kuntha, C. (1977). The effect of some commonly used pesticide in the paddy field on Proxenus hennia Swinhoe, a potential biological control agent agains water lettuce (Pistia stratiotes L). Biotrop. Bogor.

Mangoendihardjo, S., Setyawati, O., Syed, S.A. and Sosromarsono, S. (1979). Insects and fungi associated with some aquatic weeds in Indonesia. pp 440-446. In Proceedings, Sixth Asia-Pacific Weed Science Society Conference, July 11-17, 1977. Asian-Pacific Weed Science Society. Jakarta. Indonesia.

Mangoendiharjo, S. (1982). Insects feding on plants in various species of weeds in indonesia. Dissertation. Agricultural faculty, Gadjah Mada University. Yogyakarta.

Memmott, J., Fowler, S.V., Harman, H.M. \& Hayes, L.M. (1996). How best to release a biological control agent. pp 291-296. In Proceedings of the IX International Symposium on Biological Control of Weeds, January 1996. University of Cape Town. Stellenbosch. South Africa.

Napompeth, B. (1990). Biological control of weed in Thailand. In Symposium on Weed management, Bogor, 7-9 Juni 1989. pp 23-36. Biotrop. Bogor.

Parsons, W.T., \& Cuthbertson, E.G. (2001). Noxious Weeds of Australia. pp 698. Collingwood. The Commonwealth Scientific and Industrial Research Organisation (CSIRO) Publishing. Australia.

Queensland Government. (2016). Water lettuce. Retrieved from http://www.business.qldgov.au/indu stry/agriculture/spesies/invasiveplants/restricted/water-lettuce

[USDA-NRCS] United States Department of Agriculture - Natural Resources Conservation Service. (2012). The Plants Database. Baton Rouge, USA: National Plant Data Center.
Retrieved

from 